\title{
Hubungan lingkar pinggang dengan kadar gula darah pada guru di SMP dan SMA Eben Haezar Manado
}

\author{
${ }^{1}$ Edwin J. Ngantung \\ ${ }^{2}$ Vanda Doda \\ ${ }^{2}$ Herlina I. S. Wungouw
}

\author{
${ }^{1}$ Kandidat Skripsi Fakultas Kedokteran Universitas Sam Ratulangi Manado \\ ${ }^{2}$ Bagian Fisiologi Fakultas Kedokteran Universitas Sam Ratulangi Manado \\ Email: elgrandiosz@gmail.com
}

\begin{abstract}
Central obesity that measured by waist circumference as one of metabolic syndrome's criteria, is one of many risk factor of metabolic and cardiovascular diseases. Teacher is an occupation which has the risk of high blood glucose and visceral fat accumulation. People with obesity have a tendency to elevation of blood glucose level. The aim of this research is to understand the correlation between waist circumference and blood glucose level on teacher in Eben Haezar junior and senior christian high school Manado. This research is a cross-sectional study that was conducted on September to December 2016. Samples were collected by total sampling method. Research data were analyzed with Spearman Rank Correlation Test. There are 83 research samples which consist of 28 men $(33,7 \%)$ and 55women $(66,7 \%)$. Most of teachers experienced central obesity $(74,7 \%)$ and normal blood glucose level $(83,1 \%)$. The result of the correlation test between waist circumference and blood glucose level is $\mathrm{p}$-value $=0,9522$ and $\mathrm{r}=-0,00667981$. This study found that there is no statistically significant relationship between waist circumference and blood glucose level on teacher in Eben Haezar junior and senior christian high school Manado.
\end{abstract}

Keywords: waist circumference, blood glucose level, teachers

\begin{abstract}
Abstrak: Obesitas sentral yang diukur berdasarkan lingkar pinggang sebagai salah satu kriteria sindroma metabolik merupakan salah satu faktor risiko penyakit metabolik dan kardiovaskular. Guru merupakan pekerjaan yang berisiko mengalami peningkatan kadar gula darah dan penumpukan lemak viseral. Orang dengan obesitas memiliki faktor risiko mengalami peningkatan kadar gula darah. Penelitian ini bertujuan untuk mengetahui hubungan lingkar pinggang dengan kadar gula darah pada guru di SMP dan SMA Kristen Eben Haezar Manado. Penelitian ini merupakan penelitian potong lintang yang dilaksanakan pada bulan September-Desember 2016. Sampel diambil dengan metode total sampling. Data penelitian dianalisis dengan uji korelasi Spearman. Sampel penelitian berjumlah 83 sampel yang terdiri dari 28 sampel pria $(33,7 \%)$ dan 55 sampel wanita $(66,3 \%)$. Mayoritas guru mengalami obesitas sentral $(74,7 \%)$ dan kadar gula darah yang normal $(83,1 \%)$. Hasil Uji korelasi antara lingkar pinggang dengan kadar gula darah adalah $\mathrm{p}$-value $=0,9522$ dan $\mathrm{r}=-$ 0,00667981 . Penelitian ini menemukan bahwa tidak ada hubungan yang signifikan antara lingkar pinggang dengan kadar gula darah pada guru di SMP dan SMA Kristen Eben Haezar Manado.
\end{abstract}

Kata kunci: lingkar pinggang, kadar gula darah, guru

Lingkar pinggang merupakan ukuran antropometrik sederhana yang digunakan sebagai indeks obesitas sentral. ${ }^{1}$ Sebuah penelitian di Sumatra Barat oleh Nur 
Indrawati menemukan gambaran rata-rata lingkar pinggang, yaitu $79,05 \pm 10,86 \mathrm{~cm}$. Berdasarkan hasil pengukuran lingkar pinggang, didapat $38,6 \%$ responden mengalami obesitas. ${ }^{2}$ Obesitas sentral dengan parameter lingkar pinggang merupakan salah satu komponen sindroma metabolik. $^{3}$

Sindroma metabolik menurut International Diabetic Federation (IDF) adalah sekumpulan faktor risiko dari serangan jantung yang paling berbahaya. Federasi ini menyebutkan orang dengan sindroma metabolik mempunyai kondisi gula darah puasa yang meningkat, obesitas abdominal, kadar kolesterol yang tinggi, serta hipertensi. ${ }^{3}$ Referensi lain menyebutkan, kriteria sindroma metabolik meliputi (a) obesitas sentral (lingkar pinggang $>102 \mathrm{~cm}$ untuk pria dan $>88 \mathrm{~cm}$ untuk wanita); (b) hypertriglyceridemia (kadar trigliserida $\geq 150 \mathrm{mg} / \mathrm{dL}$ atau dalam medikasi spesifik); (c) Kadar HDL kolesterol rendah $(<40 \mathrm{mg} / \mathrm{dL}$ untuk pria and $<50 \mathrm{mg} / \mathrm{dL}$ untuk wanita, atau dalam medikasi spesifik); (d) hipertensi (tekanan darah sistolik $\geq 130 \mathrm{mmHg}$ atau tekanan darah diastolik $\geq 85 \mathrm{mmHg}$ atau dalam medikasi spesifik); (e) kadar gula darah puasa $\geq 100 \mathrm{mg} / \mathrm{dL}$ atau dalam medikasi spesifik atau sebelumnya terdiagnosis diabetes mellitus tipe $2 .^{4}$

Lingkar pinggang berkorelasi kuat dengan obesitas dan risiko kardiovaskular. Lingkar pinggang terbukti lebih efektif dalam mendiagnosis sindroma metabolik dibandingkan dengan indeks massa tubuh (IMT) dan ukuran antropometri lainnya. ${ }^{1}$ Hal ini membuktikan pengukuran lingkar pinggang merupakan cara yang mudah, murah, dan efektif dalam mendeteksi sindroma metabolik.

Orang dengan obesitas berisiko mengalami peningkatan kadar gula darah. Sebuah penelitian dilakukan oleh Triani, et al pada tahun 2016 menyatakan bahwa orang dengan obesitas memiliki faktor risiko 4 kali lebih besar mengalami peningkatan kadar gula darah dibandingkan dengan orang yang tidak obesitas. Pada penelitian ini terdapat 29 dari 85 sampel obesitas mengalami peningkatan kadar gula darah $(34,11 \%)$. Persentase ini terbilang besar bila dibandingkan dengan peningkatan kadar gula darah pada sampe yang tidak mengalami obesitas $(15,32 \%)$. Dapat disimpulkan, obesitas berhubungan erat dengan kadar gula darah. ${ }^{5}$

\section{METODE PENELITIAN}

Penelitian ini bertujuan untuk mengetahui hubungan lingkar pinggang dengan kadar gula darah pada guru di SMP dan SMA Kristen Eben Haezar Manado. Penelitian ini bersifat observasional analitik dengan metode survey dan pendekatan rancangan penelitian potong lintang. Penelitian dilakukan pada bulan September sampai Desember 2016 di SMP dan SMA Kristen Eben Haezar Manado. Populasi penelitian ini adalah semua guru-guru yang mengajar di sekolah. Terdapat 83 orang guru yang memenuhi kriteria inklusi dan bersedia berpartisipasi dalam penelitian. Variabel yang diteliti adalah lingkar pinggang dan kadar gula darah. Lingkar pinggang responden diukur secara langsung menggunakan pita ukur. Kadar gula darah yang digunakan dalam penelitian ini adalah kadar gula darah sewaktu yang diukur dengan alat GlucoDr. Data hasil pengukuran dikelompokkan dalam bentuk tabel dan diolah secara statistik menggunakan analisis Pearson bivariat.

\section{HASIL PENELITIAN}

Penelitian dilakukan di UKS sekolah. Para guru berkumpul di depan UKS mengantri untuk masuk kedalam UKS. Dalam ruangan UKS, para guru yang mengantri mengisi informed consent dan diwawancarai secara singkat untuk mengetahui identitas dan menjelasan tentang pengukuran lingkar pinggang serta kadar gula darah. Selesai diwawancara, dilakukan pengukuran lingkar pinggang di ruangan depan UKS. Kemudian guru yg mangantri masuk ke ruang belakang UKS yang dipisahkan dengan tirai untuk menjaga privasi guru sebagai responden penelitian. Peneliti kemudian melakukan pemgukuran kadar gula darah. 


\section{Karakteristik Subjek Penelitian}

Karakteristik subjek penelitian yang berpartisipasi dalam penelitian dibagi berdasarkan jenis kelamin dan umur (Tabel 1 dan 2)

Tabel 1. Karakteristik subjek berdasarkan jenis kelamin

\begin{tabular}{ccc}
\hline Jenis Kelamin & (n) & \% \\
\hline Pria & 28 & $33,7 \%$ \\
Wanita & 55 & $66,5 \%$ \\
\hline
\end{tabular}

Tabel 2. Karakteristik subjek berdasarkan umur

\begin{tabular}{ccc}
\hline Umur & (n) & \% \\
\hline$>40$ tahun & 40 & $48,2 \%$ \\
$<40$ tahun & 43 & $51,8 \%$ \\
\hline
\end{tabular}

\section{Uji Normalitas}

Uji korelasi Pearson mewajibkan distribusi data penelitian normal. ${ }^{6}$ Uji normalitas dilakukan untuk mengetahui distribusi data penelitian. Data penelitian dianalisis dengan Shapiro-Wilk Test (Tabel $3)$.

Tabel 3. Hasil uji normalitas

\begin{tabular}{ccc}
\hline Variabel & W & Nilai p \\
\hline Lingkar Pinggang & 0,98996 & 0,7736 \\
Kadar Gula Darah & 0,75927 & $2,412 \times 10^{-10}$ \\
\hline
\end{tabular}

Berdasarkan Tabel 3, didapatkan hasil uji normalitas untuk data lingkar pinggang adalah nilai $\mathrm{p}=0,7736$ dengan nilai $\alpha=$ 0,05 . Nilai $\mathrm{p}$ didapatkan lebih besar dari nilai a sehingga data lingkar pinggang berdistribusi normal. ${ }^{6}$ Pada Tabel 3 juga didapat hasil uji normalitas untuk data kadar gula darah adalah nilai $\mathrm{p}=2,412 \times 10$ 10 dengan nilai $\alpha=0,05$. Nilai didapatkan lebih kecil dari nilai $\alpha$ sehingga data kadar gula darah berdistribusi tidak normal. ${ }^{6}$

\section{Nilai Lingkar Pinggang dan Kadar Gula Darah}

Nilai lingkar pinggang dan kadar gula darah dijabarkan dalam bentuk tabel sebelum dimasukkan dalam perangkat lunak untuk diolah secara statistik. Nilai rata-rata lingkar pinggang dan kadar gula darah dapat dilihat pada tabel 4, data frekuensi lingkar pinggang dapat dilihat pada tabel 5 serta data frekuensi kadar gula darah dapat dilihat pada tabel 6 .

Tabel 4. Nilai rata-rata lingkar pinggang dan kadar gula darah

\begin{tabular}{lc}
\hline \multicolumn{1}{c}{ Variabel } & Mean \\
\hline Lingkar Pinggang & \\
Pria & $92,21 \mathrm{~cm}$ \\
Wanita & $89,4 \mathrm{~cm}$ \\
Kadar Gula Darah & \\
Pria & $105 \mathrm{mg} / \mathrm{dL}$ \\
Wanita & $103 \mathrm{mg} / \mathrm{dL}$ \\
\hline
\end{tabular}

Tabel 5. Data frekuensi lingkar pinggang guru-guru

\begin{tabular}{ccc}
\hline $\begin{array}{c}\text { Lingkar } \\
\text { pinggang }(\mathrm{cm})\end{array}$ & $(\mathrm{n})$ & $\%$ \\
\hline Normal & 21 & $25,3 \%$ \\
Obesitas & 62 & $74,7 \%$ \\
\hline
\end{tabular}

Tabel 6. Data frekuensi kadar gula darah guru-guru.

\begin{tabular}{ccc}
\hline Kadar Gula Darah & (n) & \% \\
\hline Normal & 69 & $81 \%$ \\
Hiperglikemia & 2 & $2,4 \%$ \\
Hipoglikemia & 12 & $14,5 \%$ \\
\hline
\end{tabular}

\section{Analisis Statistik Hubungan Lingkar Pinggang dan Kadar Gula Darah}

Data dianalisis menggunakan uji korelasi Spearman. Hasil uji korelasi Spearman dapat dilihat pada tabel 6 .

Tabel 6. Hasil Interpretasi uji korelasi Spearman

\begin{tabular}{cccc}
\hline n & Variabel & $\begin{array}{c}\text { Spearman- } \\
\text { rho }\end{array}$ & Nilai p \\
\hline Lingkar & & \\
83 & $\begin{array}{c}\text { pinggang } \\
\text { dan kadar } \\
\text { gula darah }\end{array}$ & $-0,00667981$ & 0,9522 \\
\hline
\end{tabular}


Berdasarkan Tabel 6, diperoleh nilai $\mathrm{p}$ $=0,9522$ dengan besar nilai $\alpha=0,05$. Hal tersebut menunjukan bahwa tidak ada hubungan monotonik antara lingkar pinggang dan kadar gula darah. Tabel 6 juga menampilkan nilai korelasi data, yaitu $-0,00667981$. Nilai ini menunjukan korelasi antara lingkar pinggang dengan kadar gula darah sangat kecil dan bernilai negative. ${ }^{6}$

\section{BAHASAN}

Penelitian ini bertujuan untuk mengetahui adanya hubungan antara lingkar pinggang dengan kadar gula darah pada guru di SMP dan SMA Kristen Eben Haezar Manado. Tiap guru yang memenuhi kriteria diukur lingkar pinggangnya dengan meteran dan kadar gula darahnya dengan alat GlucoDr. Jumlah sampel penelitian sebanyak 83 sampel dan kebanyakan sampel berjenis kelamin wanita $(66,3 \%)$, berbeda dengan penelitian lain yang mengambil sampel wanita yang lebih besar, yaitu $82,6 \%$ dan 78,5\%.1,2 Berdasarkan karakteristik usia, sampel dalam penelitian ini mayoritas berusia $<40$ tahun $(51,8 \%)$. Pada penelitian yang lain, sampel diambil dengan kriteria range umur $30-60$ tahun. ${ }^{1}$

Setelah dilakukan Penelitian, didapatkan rata-rata lingkar pinggang sampel pria melebihi normal, yaitu $92,21 \mathrm{~cm}$ dengan range $72-116 \mathrm{~cm}$. Lebih dari setengah jumlah sampel pria mengalami obesitas sentral $(57,3 \%)$. Pada sampel wanita didapatkan rata-rata lingkar pinggang $89,4 \mathrm{~cm}$ yang tergolong pada obesitas sentral. Sebesar $83,6 \%$ sampel wanita mengalami obesitas sentral dengan range lingkar pinggang antara $67-110 \mathrm{~cm}$. Hal ini menunjukan obesitas sentral lebih banyak terdapat pada wanita dari pada pria.

Gambaran obesitas sentral pada guru di SMP dan SMA Eben Haezar Manado menjadi hal yang perlu diperhatikan. Obesitas sentral dengan parameter lingkar pinggang merupakan faktor risiko dari berbagai penyakit metabolik dan kardiovaskular. $^{4,7,8}$ Hal ini menunjukan guru-guru di SMP dan SMA Eben Haezar Manado memiliki risiko yang lebih besar untuk mengalami penyakit tersebut. Hal ini menjadi lebih relevan jika faktor risiko obesitas sentral dibarengi dengan faktor aktivitas fisik dan olahraga. ${ }^{7,8}$ Guru SMP dan SMA mengabiskan \pm 48 jam seminggu untuk mengajar di kelas. Para guru juga tidak punya waktu untuk berolahraga setelah melakukan pekerjaannya. Aktivitas fisik semacam ini bisa digolongkan dalam sedentary lifestyle yang merupakan salah satu faktor risiko berbagai penyakit. ${ }^{8}$ Padahal dengan olahraga, risiko penyakit metabolik dapat diturunkan. Berbagai faktor risiko yang telah disebutkan dapat menjadi bahan edukasi untuk meningkatkan kesadaran para guru di SMP dan SMA Eben Haezar Manado tentang bahaya penyakit metabolik dan kardiovaskular.

Penelitian ini juga menunjukan gambaran kadar gula darah guru SMP dan SMA Eben Haezar Manado. Delapan puluh tiga koma satu persen sampel memiliki kadar gula darah yang normal. Walaupun demikian, terdapat 2 orang dari sampel yang memiliki kadar gula darah yang melebihi batas normal dan 12 orang yang memiliki kadar gula darah yang kurang dari batas normal $(\leq 70 \mathrm{mg} / \mathrm{dL}) .{ }^{9}$ Walaupun kebanyakan guru memiliki kadar gula darah yang normal tetapi tidak sedikit yang memiliki gangguan pada kadar gula darahnya. Setidaknya 16,9\% guru SMP dan SMA Eben Haezar Manado memerlukan edukasi tentang pentingnya pola makan yang teratur untuk menjaga kadar gula darah agar tetap berada pada kadar normalnya. Informasi tentang makanan dengan indeks glikemik juga merupakan hal yang perlu untuk diperhatikan. Mengkonsumsi makanan dengan indeks glikemik yang tinggi dapat meningkatkan kadar gula dalam darah. Edukasi tentang pola makan dan bahan makan yang dikonsumsi menjadi pilar utama pengendalian kadar gula darah. ${ }^{10}$ Edukasi seperti ini juga dibutuhkan untuk menjaga kesadaran masyarakat yang tinggi tentang penyakit metabolik.

Pada penelitian yang dilakukan peneliti, dilakukan uji korelasi dengan Uji Spearman Rank Correlation terhadap data 
dan diperoleh $p$-value $=0,9522$. Penemuan dalam penelitian ini menolak $\mathrm{H}_{1}$. Hal ini juga membuktikan tidak ada hubungan yang signifikan antara lingkar pinggang dengan kadar gula darah.

Penelitian yang dilakukan oleh Lipoeto, et al pada 2007 menemukan bahwa tidak ada hubungan antara lingkar pinggang dengan kadar gula darah ( $p$-value $>0,05)$. Penelitian ini dilaksanakan dengan design potong lintang. Sampel yang diambil berusia lebih dari 20 tahun dan berjumlah 70 sampel. Data kadar gula darah diambil melalui pengambilan darah vena setelah sampel diminta berpuasa dari pukul 20.00 dan biokimia darah diperiksa di laboratorium biokimia. Penelitian ini mendapatkan hasil $98,57 \%$ sampel memiliki kadar glukosa normal $(<110$ $\mathrm{mg} / \mathrm{dl}$ ) sedangkan sampel yang diduga menderita toleransi glukosa terganggu (kadar gula darah puasa $110-125 \mathrm{mg} / \mathrm{dl}$ ) sebanyak $1,43 \%$. Hasil penelitian ini selaras dengan penelitian yang dilakukan oleh peneliti. Penemuan ini menunjukan distribusi lemak tidak dapat dijadikan indikator keadaan metabolisme karbohidrat dalam tubuh walaupun secara teori dapat dijelaskan bagaimana penimbunan lemak viseral dapat meningkatkan kadar gula darah melalui proses resistensi insulin. ${ }^{2}$

Peningkatan lingkar pinggang dan penurunan kadar gula darah dapat dijelaskan melalui pejalanan penyakit diabetes mellitus tipe 2 atau melalui teori tentang adipokin. Jaringan lemak merupakan jaringan endokrin yang mensekresikan adipokin. ${ }^{11}$ Peningkatan jaringan lemak menyebabkan peningkatan sekresi adipokin. Adipokin mempunyai efek untuk meningkatkan resistensi insulin ataupun menurunkannya. Adipokin yang memiliki efek meningkatkan resistensi insulin adalah TNF- $\alpha$ dan resistin. Adipokin yang memiliki efek menurunkan resistensi insulin adalah adiponektin dan leptin . Kadar gula darah yang tidak meningkat atau bahkan turun merupakan efek dari adiponektin sebagai derivat adipokin yang paling banyak. ${ }^{12}$

Peningkatan produksi adiposit menyebabkan produksi asam lemak bebas dan adipokin. Hal ini menyebabkan peningkatan resistensi insulin. Awalnya, pankreas masih menjalankan tugas dalam sekresi insulin yang lebih untuk menjaga agar kadar gula dalam darah tetap berada pada keadaan normal. Namun lamakelamaan pankreas mengalami penurunan fungsi dan produksi insulin menurun secara bertahap. Pada tahap inilah, hiperglikemia dapat dideteksi. ${ }^{2,13}$ Penggunaan lingkar pinggang sebagai variabel merupakan suatu kelebihan penelitian ini. Pengukuran lingkar pinggang menjadi pengukuran antropometri sederhana yang efektif, mudah, dan murah yang digunakan sebagai indikator sindroma metabolik dibandingkan dengan indikator-indikator yang lain seperti indeks massa tubuh. Prosedur pengukuran lingkar pinggang mudah untuk dimengerti oleh sampel sehingga sampel dapat lebih kooperatif.

Penelitian ini menggunakan kadar gula darah sewaktu sebagai parameter kadar gula darah. Indikator kadar gula darah yang digunakan dalam berbagai penyakit metabolik misalnya diabetes mellitus atau sindroma metabolik adalah kadar gula darah puasa $(\leq 126 \mathrm{mg} / \mathrm{dL}) .3 \mathrm{Hal}$ ini dapat menjadi faktor yang mempengaruhi interpretasi kadar gula darah dan mempengaruhi hasil kadar gula darah.

\section{SIMPULAN}

Dari hasil penelitian dapat disimpulkan bahwa tidak terdapat hubungan antara lingkar pinggang dengan kadar gula darah pada guru di SMP dan SMA Kristen Eben Haezar Manado.

\section{SARAN}

Dapat dilakukan penelitian yang lebih lanjut dengan melibatkan variabel yang berbeda sehingga hasil penelitian berikutnya menjadi lebih luas. Contohnya dengan mengelompokan sampel dalam beberapa kelompok aktivitas fisik atau dengan menggunakan variabel kadar gula darah puasa. Penelitian selanjutnya menggunakan metode yang lebih akurat mengukur penumpukan lemak abdominal. 
Karena tingginya angka obesitas sentral pada guru maka diperlukan edukasi tentang risiko obesitas dan pola hidup sehat sebagai upaya untuk menghidarinya.

\section{DAFTAR PUSTAKA}

1. Jalal F, Liputo N, Susanti N, Oenzil F. Hubungan lingkar pinggang dengan kadar gula darah, trigliserida dan tekanan darah pada etnis Minang di kabupaten Padang Pariaman, Sumatera Barat.2006.

2. Lipoeto N, Yerizel E, Edward Z, Widur I. Hubungan nilai antropometri dengan kadar glukosa darah. Medika 2007:p10-28.

3. International Diabetes Federation. The IDF consensus worldwide definition of the Metabolic Syndrome. Belgium. 2006:4-11.

4. Eckel R. Metabolic Syndrome. In: Kasper D, Hauser S, Jameson J, Fauci A, Longo D, Loscalso J, editors. Harrison's Principles of Internal Medicine. 19th ed. McGraw-Hill Education; 2015.p.2449-50.

5. Triani SK, Widyatmoko S, Jatmiko SW. Perbedaan nilai kadar gula darah sewaktu pada dewasa obesitas dan non obesitas di kecamatan Jebres kota Surakarta. Mei 2016. Available from: http://eprints.ums.ac.id/43347. diakses pada 13 Desember 2016.

6. Sujarweni VW. Statistik untuk kesehatan. Gava Media;2015.h.80-92.

7. Antman E, Loscalzo J. Coronary and peripheral vascular disease. In: Kasper D, Hauser S, Jameson J, Fauci
A, Longo D, Loscalso J, editors. Harrison's Principles of Internal Medicine. 19th ed. McGraw-Hill Education; 2015.p.1578

8. Libby $\mathbf{P}$. Coronary and peripheral vascular disease. In: Kasper D, Hauser S, Jameson J, Fauci A, Longo D, Loscalso J, editors. Harrison's Principles of Internal Medicine. 19th ed. McGraw-Hill Education; 2015.p.291e-6.

9. Cryer P, Davis S. Hypoglycemia. In: Kasper D, Hauser S, Jameson J, Fauci A, Longo D, Loscalso J, editors. Harrison's Principles of Internal Medicine. 19th ed. McGraw-Hill Education; 2015.p.2430.

10.Powers A. Diabetes mellitus: management and therapies. In: Kasper D, Hauser S, Jameson J, Fauci A, Longo D, Loscalso J, editors. Harrison's Principles of Internal Medicine. 19th ed. McGraw-Hill Education; 2015.p.2409.

11.Sherwood L. Fisiologi manusia: dari sel ke sistem. Ed 6. EGC; 2009.h.705.

12.Darmayanti D. Korelasi lingkar pinggang dan rasio pinggang panggul terhadap HbAlc pada karyawan pria dewasa sehat di universitas Sanata Dharma.Yogyakarta 2014:h.1-47.

13.Powers A. Diabetes Mellitus: diagnosis, classification, and pathophysiology. In: Kasper D, Hauser S, Jameson J, Fauci A, Longo D, Loscalso J, editors. Harrison's Principles of Internal Medicine. 19th ed. McGrawHill Education; 2015.p.2402-5. 